\title{
GAMMA RAY MUTAGENESIS IN A STRAIN OF ESCHERICHIA COLI DEFICIENT IN DNA POLYMERASE I
}

\author{
B. A. BRIDGES, and R. P. MOTTERSHEAD \\ M.R.C. Cell Mutation Unit, University of Sussex, Folmer, Brighton BN1 $9 Q H$, Sussex
}

Received 29.xi.71

\section{INTRODUCTION}

IT is now reasonably clear that Escherichia coli bacteria possess at least two distinct methods of repairing single-stranded breaks induced in DNA by ionising radiation. One is relatively slow, requires growth conditions and does not take place in RecA or ExrA strains (McGrath and Williams, 1966; Kaplan, 1966; Kapp and Smith, 1970). Although the recA gene also affects genetic recombination, it would appear that recombination between existing chromosomes is not necessary for RecA +-dependent repair of single strand DNA breaks induced by ionising radiation (Bridges, 1971). Moreover, there is evidence that such breaks may remain unrepaired until the subsequent DNA replication (Bridges, Green and Munson, 1971; Green, Bridges and Riazuddin, 1971; Hudnik-Plevnik and Djorgevic, 1971). Another pathway for the repair of single-strand breaks has recently been demonstrated by Town, Smith and Kaplan (1971) to depend on DNA polymerase I (Kornberg enzyme). This type of repair is extremely rapid but does not appear to be able to repair a minority class of breaks which are reparable only by the RecA+-dependent system. In the absence of DNA polymerase I many breaks normally repaired rapidly by it are repaired slowly by the RecA+-dependent pathway. It thus seems possible to differentiate breaks into at least two classes, "simple" breaks reparable either rapidly by DNA polymerase I or slowly by $\operatorname{RecA}^{+} / \mathrm{ExrA}^{+}-$dependent repair, and " complex" breaks reparable only by RecA+/ExrA+-dependent repair. Of course other genes and enzymes than those so far mentioned are likely to be involved in both pathways (e.g. polynucleotide ligase).

It has been shown that ExrA strains of $E$. coli have about 5 per cent. of the mutability toward ionising radiation of ExrA+ strains (Bridges, Law and Munson, 1968). The RecA strain NG 30 has been reported to be nonmutable by X-rays (Kondo, 1968), and this has been confirmed with a RecA derivative of $E$. coli WP2 (Rothwell and Bridges, unpublished result). This suggests that mutations do not arise to any extent during repair involving DNA polymerase I but only at an error-prone step during RecA+/ExrA+dependent repair. This being so, one may pose the question whether ionising radiation mutagenesis is primarily determined by the lesion (i.e. a "complex" break) or the repair system (i.e. $\operatorname{RecA}+/ \operatorname{ExrA}^{+}$-dependent repair). If it is a function of the repair system, whatever the lesion operated on, then one would predict a higher mutability to ionising radiation in strains deficient in DNA polymerase I since the repair of some of the "simple" breaks would be left to the error-prone RecA+/ExrA+-dependent system. If, on the other hand, mutagenicity were a function solely of the lesion, then mutability would be no greater in the absence of polymerase I repair and might even 
be less if the $\operatorname{Rec} \mathrm{A}^{+} / \mathrm{ExrA}^{+}$-dependent system acted preferentially on lesions normally repaired by polymerase $\mathrm{I}$.

In a short communication Kondo (1968) reported that $\mathrm{R} 15$, a res $A$ derivative of $\mathrm{H} / \mathrm{r}$ 30- $\mathrm{R}$ deficient in DNA polymerase $\mathrm{I}$ ( $\mathrm{K}$ ato and Kondo, 1970), was mutable by gamma radiation at the same rate as its parent. No actual data were given, however, and the mutation system used by Kondo has certain disadvantages in this particular strain (see below). The present paper reports new data obtained with R15 showing that it is in certain circumstances more mutable than $\mathrm{H} / \mathrm{r} 30-\mathrm{R}$.

\section{Materials AND METhods}

\section{(a) Organisms}

Escherichia coli $\mathrm{H} / \mathrm{r} 30-\mathrm{R}$ argF and its derivative $\mathrm{R} 15 \arg F \operatorname{res} A$ (deficient in DNA polymerase I activity (Kato and Kondo, 1967, 1970)) were kindly supplied by Dr S. Kondo; CM 631 is a spontaneous phenotypic $\mathrm{Arg}^{+}$ mutant of R15 containing an amber suppressor which suppresses both the $\arg F$ and $\operatorname{res} A$ mutations.

(b) Cultural techniques

$\mathrm{H} / \mathrm{r} 30-\mathrm{R}$ and $\mathrm{CM} 631$ were grown with aeration to mid-logarithmic phase $\left(\sim 2 \times 10^{8}\right.$ bacteria $/ \mathrm{ml}$.) in Oxoid Nutrient Broth No. 2. The bacteria were concentrated and washed by membrane filtration and resuspended in phage buffer (Boyle and Symonds, 1969) at about $2 \times 10^{9} / \mathrm{ml}$. for irradiation at room temperature. R15 was grown from a single bacterium to a small colony and then inoculated into broth without allowing the organisms to enter stationary phase. All incubations were at $37^{\circ} \mathrm{C}$.

For selecting $\mathrm{Arg}^{+}$mutants, about $6 \times 10^{8}$ bacteria were plated on to Davis and Mingioli (1950) minimal agar supplemented with 5 per cent. Oxoid Nutrient Broth (not No. 2). Prototrophic mutants appeared after 48 hours as distinct colonies in a lawn of residual auxotrophic growth. Viable counts were performed using the same medium after appropriate dilution. Induced mutant frequencies were determined after correction for spontaneous mutants which were of two classes: (i) pre-existing $\mathrm{Arg}^{+}$ mutants which were estimated by plating the unirradiated suspension on unsupplemented agar and which were assumed to be inactivated at the same rate as the auxotrophic population in the case of $\mathrm{H} / \mathrm{r} 30-\mathrm{R}$ and (being phenotypically $\mathrm{Res}^{+}$) at the same rate as a typical $\mathrm{H} / \mathrm{r} 30-\mathrm{R}$ population in the case of R15, (ii) " plate mutants" which arose during residual auxotrophic growth and which were taken to be a constant number per plate since they are known to be independent of the initial number of auxotrophs plated within fairly wide limits.

Streptomycin resistant $\left(\mathrm{Str}^{\mathrm{r}}\right)$ mutants were assayed by a method similar to that of Witkin (1969). Approximately $5 \times 10^{8}$ bacteria were plated in $12 \mathrm{ml}$. of melted ( $45^{\circ}$ C.) Oxoid Nutrient Broth No. 2 with 1.5 per cent. Davis "New Zealand" agar. After solidification, a further $12 \mathrm{ml}$. of the medium was solidified as a second layer. After 4.5 hours of incubation at $37^{\circ} \mathrm{C}$. to allow expression of newly induced mutants, $0.3 \mathrm{ml}$. of a 6 per cent. solution of Glaxo streptomycin sulphate was spread on to the agar surface. Mutant colonies were counted after 5 days. Survival was determined in the same medium without streptomycin after 24 hours' incubation. The spontaneous mutation frequency was low, less than $10^{-8}$. 


\section{(c) Irradiation}

The bacterial suspension was exposed to Cobalt-60 gamma radiation at a rate of $4.6 \mathrm{krads}$ per minute with continuous aeration at room temperature.

\section{RESULTS}

\section{(a) Induction of $\mathrm{Arg}^{+}$mutants}

This system as used by Kondo has two disadvantages when strain R15 is used and they both arise from the fact that the amber suppressors not only suppress $\arg F$ but also the polymerase gene $\operatorname{res} A$. Thus Arg ${ }^{+}$mutants newly induced could conceivably be favourably selected as a result of gamma irradiation, although we have made a correction to eliminate this (see below). A more important disadvantage stems from the fact that $\mathrm{R} 15$ rapidly loses viability when allowed to reach the stationary phase of growth. The $\mathrm{Arg}^{+}$ Res ${ }^{+}$suppressor mutants do not lose viability and are thus enriched in the surviving population resulting in a very high background of $\mathrm{Arg}^{+}$bacteria, an apparent mutator-like effect. To prevent this, cultures were grown from a single bacterium without at any time being allowed to become stationary.

It was found that R15 showed more variability in its inactivation by gamma radiation than other strains we have studied. As can be seen from fig. 1, exponentially growing R15 bacteria were more sensitive to the lethal action of gamma radiation than $\mathrm{H} / \mathrm{r} 30-\mathrm{R}$, the mean increase in sensitivity for the three experiments carried out being $1 \cdot 5$. These inactivation curves are not intended to give a full picture of radiation killing (for which results at higher doses would have been required) but rather to show the levels of inactivation at which mutation induction was scored. We did not wish to use surviving fractions less than about $0 \cdot 1$ for these experiments. In addition to showing greater sensitivity to inactivation, R15 bacteria were also more mutable than $\mathrm{H} / \mathrm{r} 30-\mathrm{R}$, a mean increase (from three experiments) of $2 \cdot 2$ based on the dose required to induce a mutation frequency of $3 \times 10^{-7}$. If the mutation frequency at a particular dose was used as a basis for comparison, R15 was more mutable than $\mathrm{H} / \mathrm{r} 30-\mathrm{R}$ by a factor of 3 at 2 krads, and 4.3 at 4 krads. These figures are based on the assumption that a newly induced $\mathrm{Arg}^{+}$mutant is as sensitive to radiation as the R15 Arg- bacteria, i.e. that the suppression of the res $A$ gene by the induced amber suppressor is not effective until after the events which irrevocably decide whether or not the cell will survive. If, on the other hand, full repair by the resA pathway occurs in the newly induced Arg' mutants, then they would be as resistant as an $\mathrm{H} / \mathrm{r} 30-\mathrm{R}$ population. The real mutation frequency dose-response curve would then be the broken line in fig. 1, which would mean an increase in sensitivity by a factor of 1.7 (to achieve a frequency of $3 \times 10^{-7}$ ) over the Res ${ }^{+}$strain $H / r 30-R$. The real curve probably lies between these two extremes $(1.7$ and $2 \cdot 2)$, approximately a two-fold difference in sensitivity.

\section{(b) Induction of Str mutants}

This assay of mutability does not possess the disadvantage of the $\mathrm{Arg}^{+}$ system, but nevertheless gave similar results with growing bacteria (fig. 2). The average increase in sensitivity to killing for $\mathrm{R} 15$ compared to $\mathrm{H} / \mathrm{r}$ $30-\mathrm{R}$ was $1 \cdot 3$, and in sensitivity to mutation, 1.53 (based on the dose yielding 
a mutation frequency of $2 \times 10^{-7}$ ). R15 was about 1.76 times more mutable than the suppressed $\mathrm{Res}^{+}$strain CM 631 isolated as an $\mathrm{Arg}^{+}$mutant of R15. As CM 631 was a spontaneous mutant of R15 it is likely to be more nearly isogenic with $\mathrm{R} 15$ than is $\mathrm{H} / \mathrm{r} 30-\mathrm{R}$ from which $\mathrm{R} 15$ was derived by Nmethyl-N'-nitro-N-nitrosoguanidine mutagenesis.

It is clear, therefore, that exponentially growing $\mathrm{R} 15$ bacteria deficient

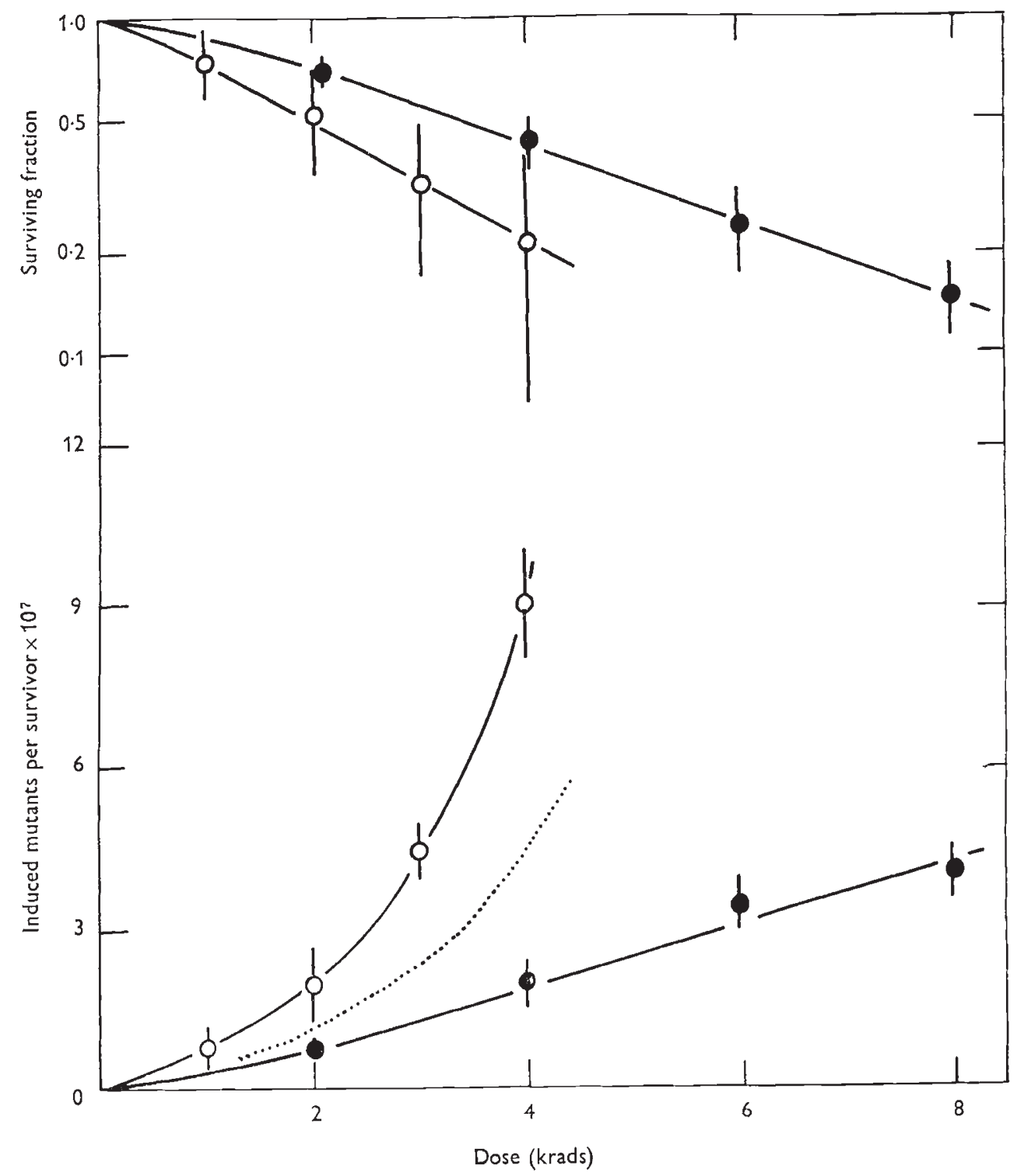

FIG. 1.-Survival and induction of $\mathrm{Arg}^{+}$mutants in logarithmic phase E. coli $\mathrm{H} / \mathrm{r} 30-\mathrm{R}(\mathbf{O})$ and $\mathrm{R} 15 \operatorname{res} A(O)$ after gamma irradiation. The dotted line indicates the real mutation curve for $\mathrm{R} 15$ if it is assumed that newly induced $\mathrm{Arg}^{+}$mutants are inactivated at the same rate as $H / r \quad 30-R$ and not $R 15$. The vertical lines indicate the standard errors of the means of three independent experiments. 


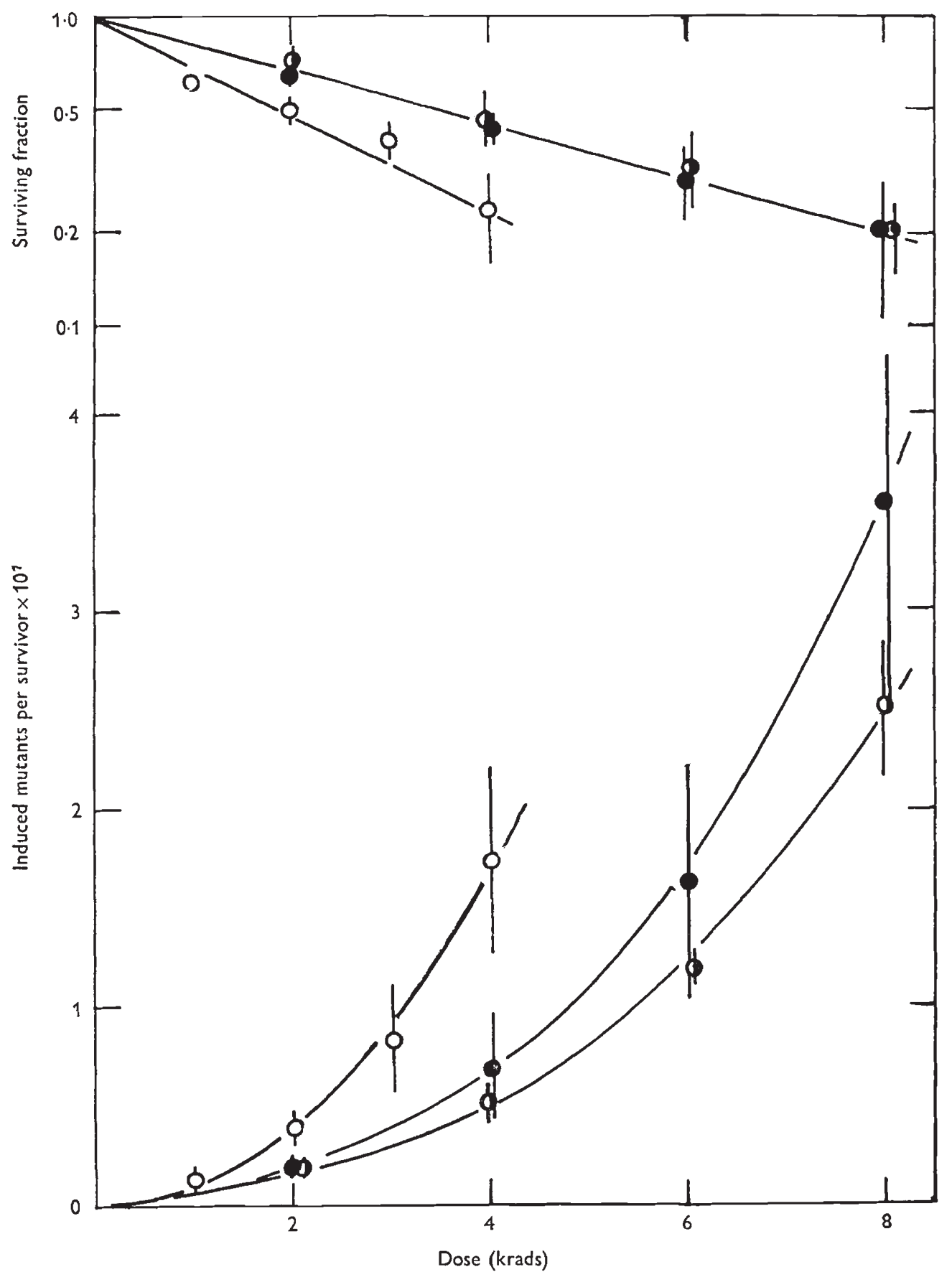

FIG. 2.-Survival and induction of $\operatorname{Str}^{\mathrm{r}}$ mutants in logarithmic phase E. coli $\mathrm{H} / \mathrm{r} 30-\mathrm{R}(\boldsymbol{O})$, $\mathrm{R} 15$ res $A(\mathrm{O})$ and $\mathrm{CM} 631(\mathbf{0})$. The vertical lines indicate the standard errors of the means of three or four independent experiments. 


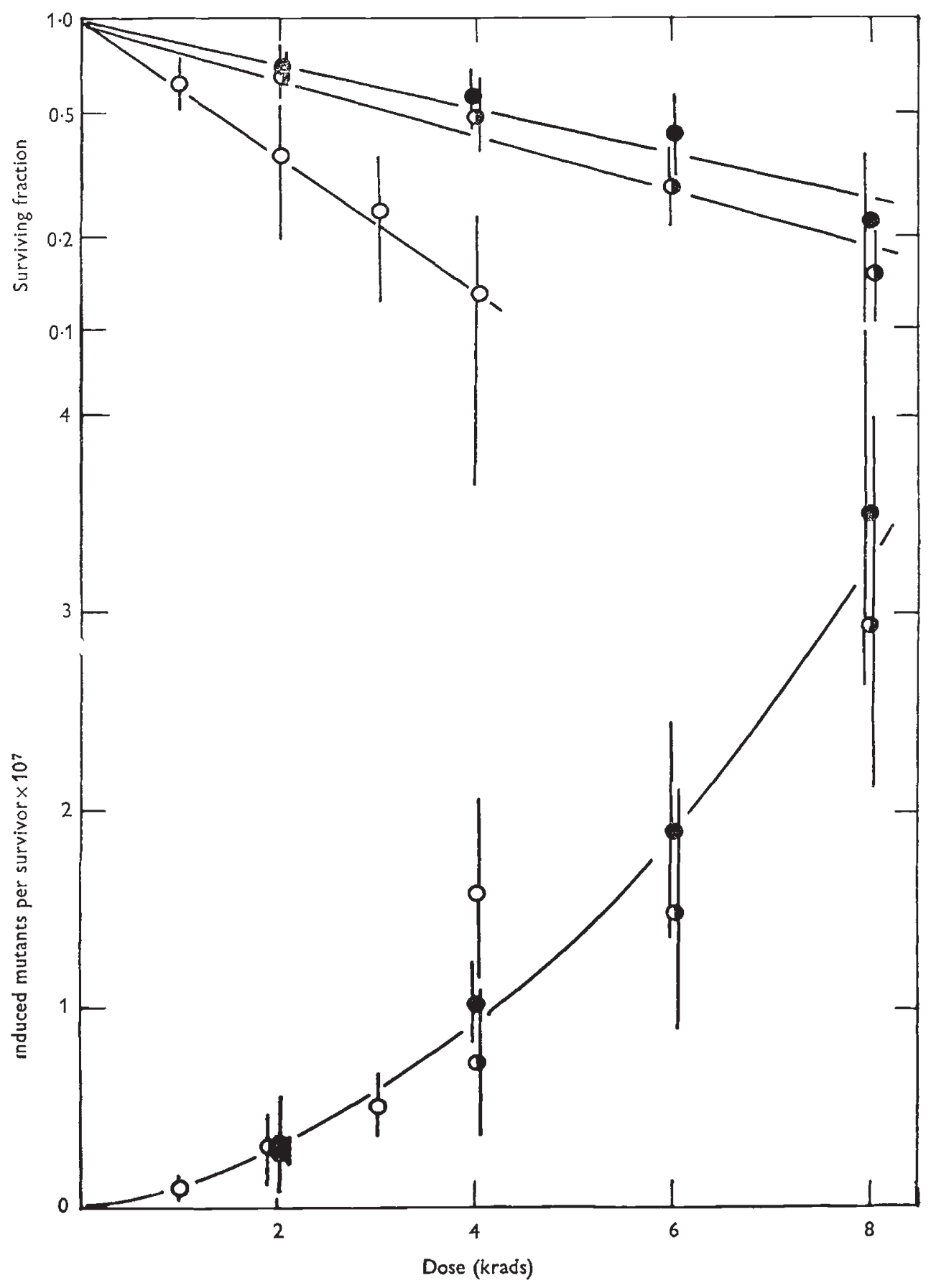

FIG. 3.-Survival and induction of $\operatorname{Str}^{\mathrm{r}}$ mutants in stationary phase E. coli $\mathrm{H} / \mathrm{r} 30-\mathrm{R}(\boldsymbol{O})$, $\mathrm{R} 15$ res $A(\mathrm{O})$ and $\mathrm{CM} 631(\mathrm{O})$. The vertical lines indicate the standard errors of the means of four independent experiments. 
in DNA polymerase I possess increased mutability to ionising radiation. The result of Kondo (1968) in which no increase was observed was obtained using starved stationary phase bacteria. Green, Gray, Murden and Bridges (1971) have shown that R15 is much more sensitive to ultraviolet light in the stationary phase than in the exponential growth phase, and Green (personal communication) has found that this is also true for gamma radiation. On the basis of the results described in the introduction, one would therefore

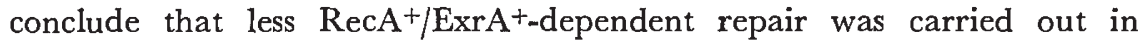
stationary phase R15 bacteria and that, since gamma ray mutagenesis is also RecA+/ExrA+-dependent, fewer mutants would be induced compared with growing bacteria.

Experiments with the $\operatorname{Str}^{\mathrm{r}}$ system have shown this to be true. Fig. 3 shows inactivation and mutation induction by gamma radiation for stationary phase (overnight, aerated, nutrient broth cultured) $\mathrm{R} 15$ and $\mathrm{H} / \mathrm{r} 30-\mathrm{R}$. $\mathrm{R} 15$ may be seen to be more sensitive to the lethal action of gamma radiation than either $\mathrm{H} / \mathrm{r}$ 30-R or GM631. There was, however, no significant difference in mutation induction between $\mathrm{R} 15$ and $\mathrm{H} / \mathrm{r} 30-\mathrm{R}$ nor between $\mathrm{R} 15$ and CM 631 at doses up to 4 krads. The result of Kondo is thus confirmed and it is clear that with stationary phase bacterit the absence of polymerase I-repair has little or no effect on gamma ray mauagenesis.

\section{Discussion}

It has been shown that exponentially growing bacteria of strain R15, deficient in DNA polymerase $I$, are approximately 1.5 to 2 times as gamma ray mutable as the non-deficient $\mathrm{H} / \mathrm{r} \quad 30-\mathrm{R}$ and the suppressed CM 631 whereas stationary phase cultures have similar mutabilities. If we assume no lesions are repaired by DNA polymerase $I$ in $R 15$, the increased resistance to killing of logarithmic phase compared with stationary phase bacteria is ascribed to an increased amount of $\mathrm{RecA}^{+} / \mathrm{ExrA}^{+}$-dependent repair and this is correlated with an increased frequency of induced mutations. It is therefore a reasonable deduction that a proportion of the "simple" breaks, which in a Res ${ }^{+}$strain would normally be rapidly and accurately repaired by DNA polymerase I are, in an exponentially growing polymerase-deficient strain, repaired by the $\operatorname{Rec} A^{+} / \operatorname{ExrA}^{+}$-dependent system with a finite probability of error (or mutation). Thus it is the nature of the repair system, and not necessarily of the initial lesion, which determines mutability by ionising radiation. "Simple" breaks may or may not give rise to mutations depending on how they are repaired.

We do not know the chemical nature of the "simple" breaks produced by gamma radiation, except that they are reparable by DNA polymerase I and ligase. A single strand gap with similar properties might result from excision of a pyrimidine dimer. Such gaps are normally repaired accurately (Witkin, 1966), probably by DNA polymerase I (Boyle, Paterson and Setlow, 1970; Kato and Kondo, 1970; Kanner and Hanawalt, 1970; Witkin, 1971). Occasionally, however, they may be repaired inaccurately (Nishioka and Doudney, 1969; Bridges and Mottershead, 1971), again suggesting it is the mode of repair that determines mutability. It is not, of course, excluded that where both repair pathways are operational the nature of a given lesion may determine which is most likely to act. That there are breaks 
induced by ionising radiation which cannot be repaired by simple repolymerisation (" complex" breaks) seems clear from the results of Town, Smith and Kaplan (197I). Such breaks must perforce be repaired by the error-prone $\mathrm{RecA}^{+} / \mathrm{ExrA}^{+}$-dependent pathway.

\section{Summary}

1. E. coli R15, deficient in DNA polymerase I, was between 1.5 and 2 times as mutable by gamma radiation in the logarithmic phase of growth as its parent $\mathrm{H} / \mathrm{r} 30-\mathrm{R}$ or its derivative CM $63 \mathrm{I}$ in which the polymerase mutation is suppressed.

2. This difference was not observed with stationary phase organisms.

3. We attribute the increased mutability of logarithmic phase RI5 to an increased amount of repair by the $\mathrm{RecA}^{+} / \mathrm{ExrA}^{+}$-dependent pathway, suggesting that it is the nature of the repair system that is used, and not necessarily that of the initial lesion, which determines mutability by ionising radiation.

\section{RefERENCES}

BOYLE, J. M., PATERSON, M. C., AND sETLOW, R. B. 1970. Excision repair properties of an Escherichia coli mutant deficient in DNA polymerase. Nature, 226, 708-710.

BOYLE, J. M., AND sYMONDS, N. 1969. Radiation sensitive mutants of T4D. 1. T4y: A new radiation sensitive mutant; effects of the mutation on radiation survival, growth and recombination. Mutation Res., 8, 431-439.

BRIDGES, B. A. 1971. RecA $A^{+}$dependent repair of gamma-ray damage to Escherichia coli does not require recombination between existing homologous chromosomes. $\mathcal{F}$. Bacteriol., 108, 944-945.

BRIDGES, B. A., GREEN, M. H. C., AND MUNSON, R. J. 1971. Mutation by ionizing radiation in relation to repair and replication. Proc. 4th Intern. Congr. Radiation Res., in press.

BRIDGES, B. A., LAW, J., AND MUNSON, R. J. 1968. Mutagenesis in Escherichia coli. II. Evidence for a common pathway for mutagenesis by ultraviolet light, ionizing radiation and thymine deprivation. Molec. gen. Genet., 103, 266-273.

BRIDGES, B. A., AND MOTTERSHEAD, R. 1971. RecA+-dependent mutagenesis occurring before DNA replication in UV- and gamma-irradiated Escherichia coli. Mutation Res., $13,1-8$.

DAvis, B. D., AND MiNGioli, E. s. 1950. Mutants of Escherichia coli requiring methionine or vitamin $\mathrm{B}_{12}$. F. Bacteriol., 60, 17-28.

GREEN, M. H. L., BRIDGES, B. A., AND RIAZUDDIN, s. 1971. Effect of $\gamma$-radiation on the donor ability of $\operatorname{rec} A$ and $\operatorname{rec} A^{+}$strains of Escherichia coli. F. gen. Microbiol., 66, 63-68.

GREEN, M. H. L., GRAY, W. J. H., MURDEN, D. J., AND BRIDGES, B. A. 1971. Influence of growth phase on UV induced lethality and DNA breakdown in a Kornberg polymerase deficient resA strain of Escherichia coli. Molec. gen. Genet., 112, 110-116.

HUDNIK-PLEVNIK, T. A., AND DJORDJEVIC, N. 1971. Differences between Escherichia coli B/r and Salmonella typhimurium LT-2 in the sedimentation behaviour of the deoxyribonucleic acid synthesized. F. Bacteriol., 106, 1043-1046.

KANNER, L., AND HANAWALT, P. 1970. Repair deficiency in a bacterial mutant defective in DNA polymerase. Biochem. biophys. Res. Commun., 39, 149-155.

KAPLAN, H. s. 1966. DNA-strand scission and loss of viability after X-irradiation of normal and sensitized bacteria. Proc. Natl. Acad. Sci. U.S.A., 55, 1442-1446.

KAPP, D. S., AND SMITH, K. G. 1970. Repair of radiation-induced damage in Escherichia coli. II. Effect of rec and uvr mutations on radio-sensitivity and repair of X-ray-induced single-strand breaks in deoxyribonucleic acid. 7. Bacteriol., 103, 49-54.

KATo, T., AND KONDO, s. 1967. Two types of X-ray sensitive mutants of Escherichia coli B: their pheontypic characters compared with UV sensitive mutants. Mutation Res., 4, 253-263.

KATO, T., AND KONDO, s. 1970. Genetic and molecular characteristics of X-ray sensitive mutants of Escherichia coli defective in repair synthesis. F. Bacteriol., 104, 871-881. 
KONDO, s. 1968. Mutagenicity versus radiosensitivity in Escherichia coli. Proc. 12th Intern. Cong. Genet., vol. 2, 126-127.

MGGRATH, R. A., AND WILLIAMS, R. W. 1966. Reconstruction in vivo of irradiated Escherichia coli deoxyribonucleic acid: the rejoining of broken pieces. Nature, 212, 534-535.

NISHIOKA, H., AND DOUDNEY, C. O. 1969. Different modes of loss of photoreversibility of mutation and lethal damage in ultraviolet light resistant and sensitive bacteria. Mutation Res., 8, 215-228.

TOWN, C. D., SMTTH, K. C., AND KAPLAN, H. S. 1971. DNA polymerase required for rapid rejoining of X-ray induced DNA strand breaks in vivo. Science, 172, 851 .

wITKIN, E. M. 1966. Radiation induced mutations and their repair. Science, 152, 1345 1353.

wITkIN, E. M. 1969. The mutability towards ultraviolet light of recombination-deficient strains of Escherichia coli. Mutation Res., 8, 9-14.

wrrkIN, E. M. 1971. Ultraviolet mutagenesis in strains of E. coli deficient in DNA polymerase. Nature New Biology, 229, 81-82. 